of America; Association of Medical Microbiology and Infectious Diseases Canada; Centers for Disease Control and Prevention. Infection prevention and control in health-care facilities in which hematopoietic cell transplant recipients are treated. Bone Marrow Transpl 2009;44:495-507.

7. What is a DOP/PAO test? DOP Solutions website. http:// dopsolutions.ca/dopinformation.html. Published 2015. Accessed May 22, 2015.

8. Cristina ML, Spagnolo AM, Sartini M, et al. Can particulate air sampling predict microbial load in operating theatres for arthroplasty? PLOS ONE 2012;7:e52809.

\section{Procalcitonin Is Not Useful to Discriminate Between Infectious and Noninfectious CRP Elevation in Patients with Non-Small Cell Lung Cancer}

To the Editor-Lung cancer is a leading cause of cancer-related mortality worldwide. These patients frequently encounter infection during the course of their disease. C-reactive protein (CRP) already achieves high levels in cases with lung cancer without underlying infection, so its diagnostic specificity is limited. ${ }^{1,2-4}$ Procalcitonin (PCT) has been demonstrated to discriminate between infectious and noninfectious inflammatory reactions in critically ill patients. ${ }^{1,5-9}$ However, clinical data regarding to the utility of PCT in cancer patients with elevated CRP are inconsistent.

Between January and October 2013, PCT and CRP values were measured simultaneously in 100 cases of 63 patients admitted to our department. All of these patients were suffering from non-small cell lung cancer (NSCLC) and presented with CRP elevation. They were evaluated by medical history and physical examination. Patient characteristics were analyzed from medical records. Written informed consent was not acquired due to the retrospective nature of this noninterventional study. All patients underwent chest X-ray and/or thoracic computed tomography as well as laboratory and lung function tests. If necessary, abdominal and/or pleural sonography was performed. A clinically defined infection was diagnosed with a clinically evident source of infection. Microbiological analyses were performed on blood samples, urine specimens, stool samples, sputum samples, bronchoscopy aspirates, or specimens from other body regions suggestive of infection (eg, paracentesis or thoracocentesis). Peripheral venous blood was obtained from all patients. PCT concentrations were measured with an enzyme-linked fluorescent assay (VIDAS B.R.A.H.M.S PCT; Brahms Diagnostica GmbH, Germany). PCT concentrations $<0.5 \mathrm{ng} / \mathrm{mL}$ were considered normal. CRP concentrations were determined using the CRP latex agglutination test and turbidimetry (COBAS INTEGRA System; Roche Diagnostics,
Germany). CRP concentrations $<5.0 \mathrm{mg} / \mathrm{L}$ were considered normal. Student $t$ test and Fisher's exact test were used for univariate analysis. Correlation between PCT and CRP levels was evaluated using Pearson correlation coefficients (positive correlation with $r>0$ ). Receiver operating characteristic [ROC] curve analysis was used to determine the accuracy of discrimination between infectious and noninfectious patients (area under the curve $[\mathrm{AUC}]<0.5$, no diagnostic accuracy; $\mathrm{AUC}=0.5$, low diagnostic accuracy; $\mathrm{AUC}=0.7$, moderate diagnostic accuracy; $\mathrm{AUC}=0.9$, high diagnostic accuracy). Twosided $p$-values $<0.05$ were considered statistically significant.

The mean patient age was 65.6 years, and $69.8 \%$ of patients were male. Of the total cohort, $76.2 \%$ had NSCLC stage IV and $57.1 \%$ had adenocarcinoma. Infections were observed in $79 \%$ of cases (infectious group, $n=79$ ); none of these patients had sepsis or febrile neutropenia. Among the infectious group of 79 patients, the majority of infections (47 of 79, 59.5\%) were caused by pneumonia; $14(17.8 \%)$ were caused by acute exacerbation of chronic obstructive lung disease, 12 (15.2\%) were caused by empyema; and $4(5.0 \%)$ were caused by urinary tract infection, and 2 had other causes. The simultaneous elevation of PCT and CRP was not associated with higher risk for infection (odds ratio, 0.8; 95\% confidence interval $[\mathrm{CI}], 0.26-2.55 ; P=.93$ ). The mean CRP value was not significantly higher in the infectious group compared with the noninfectious group ( 144.6 vs $108.8 \mathrm{mg} / \mathrm{L} ; P=.09$ ), whereas the mean PCT value was not significantly higher in the noninfectious group ( $0.37 \mathrm{vs} 0.50 \mathrm{ng} / \mathrm{mL} ; P=.47$ ). However, correlation between PCT and CRP values was positive in both the infectious group and the noninfectious group $(r=0.48$ and $r=0.80$, respectively). Regarding prediction of infection in NSCLC patients, the areas under the ROC curve for PCT and CRP were 0.46 and 0.59 , respectively. Thus, especially PCT was not a discriminator between having and not having infection in this patient cohort.

In clinical practice, CRP and PCT are used for the diagnosis and follow-up of infectious diseases. For the diagnosis and follow-up of sepsis, PCT is superior to $\mathrm{CRP}^{5-7}$; however, only few reports are available on lung cancer patients. Tulek et $\mathrm{al}^{2}$ evaluated CRP and PCT levels in 79 histopathologically proven NSCLC patients and 20 healthy controls. High CRP levels in noninfectious NSCLC patients were mainly related to performance status and were weakly related to tumor size. These investigators concluded that adding serum PCT measurement may contribute to exclude infections in patients with NSCLC. ${ }^{2}$ Katsuhiro et $\mathrm{al}^{9}$ investigated a total of 121 patients with advanced lung cancer treated with chemotherapy. Blood samples were obtained on the first day of fever. CRP and PCT were measured; sputum and blood cultures were collected. PCT-positive patients showed poor outcomes on antibiotic therapy. Furthermore, PCT was able to discriminate infective fever from fever due to inflammation. ${ }^{9}$

The overall aim of this study was to determine the diagnostic utility of PCT to discriminate between infectious and noninfectious CRP elevation in patients with NSCLC. 
The simultaneous elevation of PCT and CRP was not associated with infection. Correlation between PCT and CRP values was positive in both the infectious group and the noninfectious group. Thus, PCT was not a discriminator between having and not having infection.

In conclusion, the diagnostic utility of PCT to discriminate between infectious and noninfectious CRP elevation in patients with NSCLC could not be shown. Therefore, not every PCT elevation in NSCLC patients with elevated CRP is associated with infection. This knowledge could be an important factor in antimicrobial stewardship.

\section{A C KNOWLEDGMENT}

Financial support: No financial support was provided relevant to this article.

Potential conflicts of interest: All authors report no conflicts of interest relevant to this article.

\section{Katrin Scheinpflug, MD; ${ }^{1, \star}$ Enrico Schalk, MD; ${ }^{2, \star}$ Elske Grabert; ${ }^{3}$ H. Jost Achenbach, $\mathrm{MD}^{1}$}

Affiliations: 1. Department of Oncology, Clinic for Pulmonary Diseases Lostau, Germany; 2. Department of Hematology and Oncology, Medical Center, Otto-von-Guericke University Magdeburg, Germany; 3. Center for Laboratory Medicine, Microbiology, Hygiene and Human Genetics Magdeburg, Germany

* These authors contributed equally to this work

Address correspondence to Katrin Scheinpflug, MD, Lungenklinik Lostau gGmbH, Lindenstr. 2, D-39291 Lostau, Germany (katrinscheinpflug@ hotmail.com).

Infect. Control Hosp. Epidemiol. 2015;36(9):1117-1118

(c) 2015 by The Society for Healthcare Epidemiology of America. All rights reserved. 0899-823X/2015/3609-0024. DOI: 10.1017/ice.2015.134

\section{REFERENCES}

1. Penel N, Fournier C, Clisant S, N'Guyen M. Causes of fever and value of C-reactive protein and procalcitonin in differentiating infections from paraneoplastic fever. Support Care Cancer 2004; 12:593-598.

2. Tulek B, Koylu H, Kanat F, Arslan U, Ozer F. Serum C-reactive protein and procalcitonin levels in non-small cell lung cancer patients. Contemp Oncolz (Pozn.) 2013;17:68-72.

3. Srimuninnimit V, Ariyapanya S, Nimmannit A, Wonglaksanapimon S, Akewanlop C, Soparattanapaisarn N. C-reactive protein as a monitor of chemotherapy response in advanced non-small cell cancer (CML study). J Med Assoc Thai 2012;95: 199-207.

4. Hong S, Kang YA, Cho BC, Kim DJ. Elevated C-reactive protein as a prognostic marker in small cell lung cancer. Yonsei Med J 2012;53:111-117.

5. Carrol ED, Thomson AP, Hart CA. Procalcitonin as a marker of sepsis. Int J Antimicrob Agents 2002;20:1-9.

6. Nijsten MW, Olinga $\mathrm{P}$, The $\mathrm{TH}$, de Vries EG, Koops HS, Groothuis GM, Limburg PC, ten Duis HJ, Moshage $H$,
Hoekstra HJ, Bijzet J, Zwaveling JH. Procalcitonin behaves as a fast responding acute phase protein in vivo and in vitro. Crit Care Med 2000;28:458-461.

7. Maruna P, Nedelnikova K, Gürlich R. Physiology and genetics of procalcitonin. Physiol Res 2000;49:57-61.

8. Schüttrumpf S, Binder L, Hagemann T, Berkovic D, Trümper L, Binder C. Utility of procalcitonin concentration in the evaluation of patients with malignant diseases and elevated C-reactive protein plasma concentration. Clin Infect Dis 2006;43:468-473.

9. Katsuhiro M, Akiko F, Yutaka I, Yukimasa H, Kaoru I, Yuichi S, Yosuke T, Shiro F, Young HK, Tadashi M, Michiaki M. Infectious background of febrile advanced lung cancer patients who received chemotherapy. Oncol Lett 2010;1:849-853.

\section{The Slippery Slope of Mandatory Quarantine for Healthcare Workers with Exposure to Ebola_Let's Do the Math}

To the Editor-Recently in the United States, attempts have been made to place into quarantine for 21 days asymptomatic healthcare workers with exposure either to patients infected with Ebola virus or to their laboratory specimens. These actions have been taken despite the absence of scientific evidence that asymptomatic persons who may be incubating Ebola virus pose any risk of transmitting the virus to others. The selection of persons for this unwarranted isolation has been seemingly arbitrary, with policies differing from state to state. This procedure is reminiscent of some of the irrational early responses to the HIV epidemic, driven by fear, in which patients with AIDS were kept in strict isolation and were sometimes shunned in the community. ${ }^{1,2}$

Fortunately, the majority of healthcare workers in the United States who are or who have been providing care or other services for Ebola patients have not been placed into quarantine. But what if some state governors or other authorities decided to actually enforce a policy in which all healthcare workers who have cared for Ebola patients either in West Africa or in the United States were quarantined for 21 days?

Imagine the following scenario. If 10 hospital workers were involved each day with a single patient with Ebola in the United States (a conservative estimate), after 2 consecutive days of care, these individuals would have to be sent into a 21-day quarantine, because the incubation period extends from 2 to 21 days. Of course, as a consequence, other hospital workers would need to take their places. If we assume that the patient with Ebola would be hospitalized for 14 days (also a conservative estimate), then 60 additional hospital workers would eventually be needed to provide care for this 1 patienta total of 70 healthcare workers. The 70 healthcare workers would eventually spend a total of 1,470 days in quarantine, more than 4 years in total days. 